\title{
Balloon dilatation of restrictive interatrial communications in congenital heart disease
}

\author{
S A Webber, J A G Culham, G G S Sandor, M W H Patterson
}

\author{
Division of \\ Cardiology, \\ Department of \\ Paediatrics and \\ Department of \\ Radiology, British \\ Columbia's Children's \\ Hospital, Vancouver, \\ Canada \\ S A Webber \\ J A G Culham \\ G G S Sandor \\ M W H Patterson \\ Correspondence to \\ Dr S A Webber, \\ Division of Cardiology, \\ British Columbia's \\ Children's Hospital, 4480 \\ Children's Hospital, 4480 \\ Oak Street, Vanco \\ Accepted for publication \\ 10 January 199
}

\begin{abstract}
An adequate interatrial communication is necessary for survival in several forms of congenital heart disease. Three children are presented in whom blade atrial septostomy proved either technically impossible or failed to achieve adequate interatrial communication. In all three an adequate communication was obtained by a balloon dilatation technique similar to that used for pulmonary valve dilatation. In one critically ill infant with mitral atresia the procedure was life saving.
\end{abstract}

The survival of infants with certain congenital cardiac defects depends on the presence of an adequate interatrial communication. Such a communication is usually present at birth, but will often become restrictive with increasing age and an adequate communication will then have to be made. The Rashkind balloon septostomy procedure is usually successful in neonates, ${ }^{1}$ but is often ineffective after the neonatal period because the thickened atrial septum is less liable to tear. The development of the Park blade septostomy catheter means that surgical atrial septectomy can now be avoided in many of these patients. ${ }^{2}$ However, blade septostomy may prove technically impossible or result in an inadequate communication. In addition, not all cardiologists are familiar with this technique. In three children we used a balloon dilatation procedure of the atrial septum similar to that performed for pulmonary valve dilatation.

\section{Patients and methods}

The table shows the patients' details. Patient 1 had pulmonary atresia with an intact interventricular septum and a hypoplastic tricuspid valve. When he was two and a half progressive hepatic congestion due to a restrictive interatrial communication developed. Blade atrial septostomy was attempted then and again six months later. This was performed in the standard manner ${ }^{2}$ and without complication, but resulted in minimal change in atrial pressures.

Patient 2 presented with central cyanosis, circulatory collapse, and severe respiratory distress when he was eight weeks old. The arterial $\mathrm{pH}$ was $7 \cdot 0$. After vigorous resuscitation an echocardiogram showed a univentricular heart of right ventricular morphology, mitral atresia, double outlet right ventricle, and a severely restrictive interatrial communication with thickened interatrial septum. He was transferred to the cardiac catheterisation laboratory so that an adequate interatrial communication could be created. Because of the patient's age and thickening of the interatrial septum a Rashkind balloon septostomy was not attempted. It proved impossible to manipulate a Park blade septostomy catheter through the restrictive foramen ovale to the small left atrium. However, a 4 French multipurpose catheter and guide wire could be passed to the left atrium with ease. It was, therefore, decided to perform balloon atrial septal dilatation rather than introduce the Park blade catheter by transseptal puncture.

Patient 3 had been followed since birth with a diagnosis of double outlet right ventricle and a subpulmonary ventricular septal defect. Pulmonary artery banding was performed when he was six weeks old. He did well until he was one year old when he began to tire very easily. Though only modest central cyanosis was noted at rest, crying or exertion caused considerable cyanosis. Echocardiography showed only a small atrial septal defect with left to right bowing of the atrial septum. We thought that his symptoms were in part due to poor interatrial mixing and might be improved by enlargement of the interatrial communication. Blade septostomy was performed in the usual manner without technical difficulty, but because it did not significantly change atrial pressures we attempted balloon atrial septostomy.

PROCEDURE (FIGS 1 AND 2)

A similar procedure was performed in all three patients. Patient 2 was artificially ventilated because of his critical condition; the other two were given intravenous sedation and were breathing spontaneously. After percutaneous catheterisation of the right femoral vein, right and transseptal left atrial pressures and saturations were measured with a size 4 or 5 French multipurpose catheter. With the catheter in the left atrium, the catheter was exchanged for a 0.035 or 0.038 inch guide wire over which a balloon dilatation catheter was passed (Meditech UT or DC series). The table shows the catheter and balloon sizes used. In each case, the mid-portion of the balloon was positioned at the atrial septal defect by fluoroscopy and cross sectional echocardiographic guidance. All procedures were performed with a standard length $(3 \mathrm{~cm})$ balloon. This provided sufficient balloon length for stabilisation of the balloon, without placement of the proximal or distal 
Patient characteristics and results of balloon dilatation of the atrial septum ${ }^{\star}$

\begin{tabular}{|c|c|c|c|c|c|c|c|}
\hline \multirow[b]{2}{*}{ Patient } & \multirow[b]{2}{*}{ Age } & \multirow[b]{2}{*}{ Diagnosis } & \multirow{2}{*}{$\begin{array}{l}\text { Previous } \\
\text { septostomy }\end{array}$} & \multirow{2}{*}{$\begin{array}{l}\text { Balloon diameter, } \\
\text { length/catheter size }\end{array}$} & \multicolumn{2}{|l|}{ Haemodynamic data } & \multirow[b]{2}{*}{ Follow up } \\
\hline & & & & & Pre-dilatation & Post-dilatation & \\
\hline 1 & $3 \mathrm{yr}$ & PA, IVS & $\begin{array}{l}\text { RBS } 2 \text { days, } \\
\text { PBS } 2 \cdot 5 \\
\text { and } 3 \text { yr }\end{array}$ & 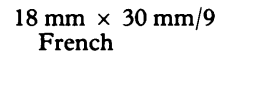 & $\begin{array}{l}\mathrm{RA} 14 \mathrm{~mm} \mathrm{Hg} \text {, LA } 5 \\
\text { mm Hg; sat LA } 91 \%\end{array}$ & $\begin{array}{r}\mathrm{RA} 10 \mathrm{~mm} \mathrm{Hg}, \mathrm{LA} 10 \\
\text { mm Hg; sat LA } 80 \%\end{array}$ & $\begin{array}{l}\text { Well age } 6 \text { yr, awaiting } \\
\text { Fontan }\end{array}$ \\
\hline 2 & $8 \mathrm{wk}$ & $\begin{array}{l}\text { MA, DORV, } \\
\text { IVS }\end{array}$ & Nil & $\begin{array}{l}8 \mathrm{~mm} \times 30 \mathrm{~mm} / 5 \\
\text { French }\end{array}$ & $\begin{array}{l}\text { RA } 4 \text { mm Hg, LA } 32 \\
\text { mm Hg; sat RA } \\
31 \%, \text { RV } 40 \%, \text { LA } \\
99 \%\end{array}$ & $\begin{array}{l}\mathrm{RA} 4 \mathrm{~mm} \mathrm{Hg}, \mathrm{LA} 12 \\
\text { mm Hg; sat RA } \\
64 \%, \mathrm{RV} 83 \%, \mathrm{LA} \\
98 \%\end{array}$ & $\begin{array}{l}\text { PAB and BHS age } 4 \\
\text { mnth, well age } 7 \\
\text { mnth }\end{array}$ \\
\hline 3 & $1 \mathrm{yr}$ & $\begin{array}{l}\text { DORV, } \\
\text { PAB, } \\
\text { spVSD }\end{array}$ & PBS 1 yr & $\begin{array}{l}15 \mathrm{~mm} \times 30 \mathrm{~mm} / 9 \\
\text { French; } 20 \mathrm{~mm} \times 30 \\
\mathrm{~mm} / 9 \text { French }\end{array}$ & $\begin{array}{l}\text { RA } 2 \text { mm Hg, LA } 10 \\
\text { mm Hg; sat RA } \\
54 \% \text {, LA } 97 \% \text {, Ao } \\
81 \%\end{array}$ & $\begin{array}{l}\text { RA } 3 \mathrm{~mm} \mathrm{Hg} \text {, LA } 5 \\
\text { mm Hg; sat RA } \\
62 \% \text {, LA } 94 \% \text {, Ao } \\
89 \%\end{array}$ & $\begin{array}{l}\text { Arterial switch/VSD } \\
\text { closure age } 3 \text { yr; wel } \\
\text { age } 4 \text { yr }\end{array}$ \\
\hline
\end{tabular}

*Patients 1 and 3 were breathing spontaneously in air and patient 2 was artificially ventilated in $90 \%$ oxygen.

Ao, aorta; BHS, Blalock-Hanlon septectomy; DORV, double outlet right ventricle; IVS, intact ventricular septum; LA, left atrium; MA, mitral atresia; PA pulmonary atresia; PAB, pulmonary artery band; PBS, Park blade septostomy; RA, right atrium; RBS, Rashkind balloon septostomy; sat, oxygen saturation; spVSD, subpulmonary ventricular septal defect.

Figure 1 Cross sectional echocardiogram from patient 3. Subcostal view showing balloon positioned across the atrial septal defect during full inflation. Guide wire was visible within the left ventricle. Atrial septum was adjacent to the mid portion of the balloon (arrowed) and no waist was evident. $G W$, guide wire; $L A$, left atrium; LV, left ventricle; $R A$, right atrium; $R V$, right ventricle.

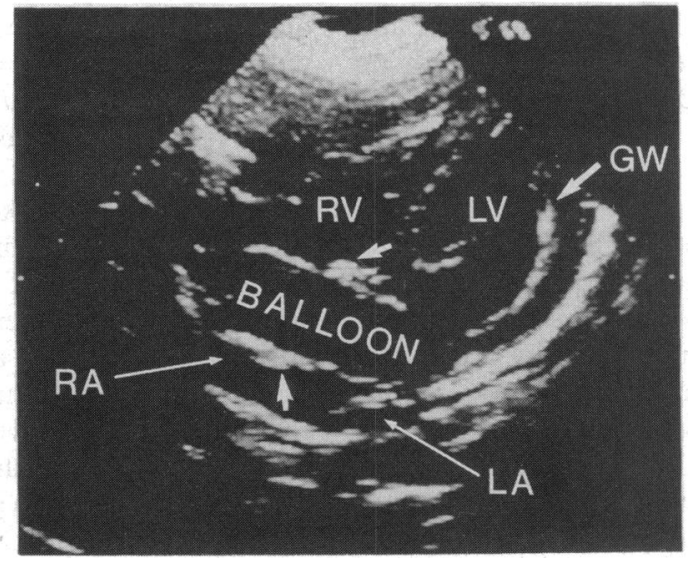

portion of the balloon in the inferior vena cava, pulmonary vein, or across the left atrioventricular valve. When a satisfactory position had been obtained, the balloon was inflated to its maximum size with inflation pressures about equal to the manufacturer's maximum recommended inflation pressure. Deflation was started as soon as the maximum balloon diameter was obtained and the waist disappeared. Each balloon was inflated three times. In patient 3, the initial inflation of the balloon resulted in stripping of the atrial septum distally along the balloon, rather than a local dilatation and tear

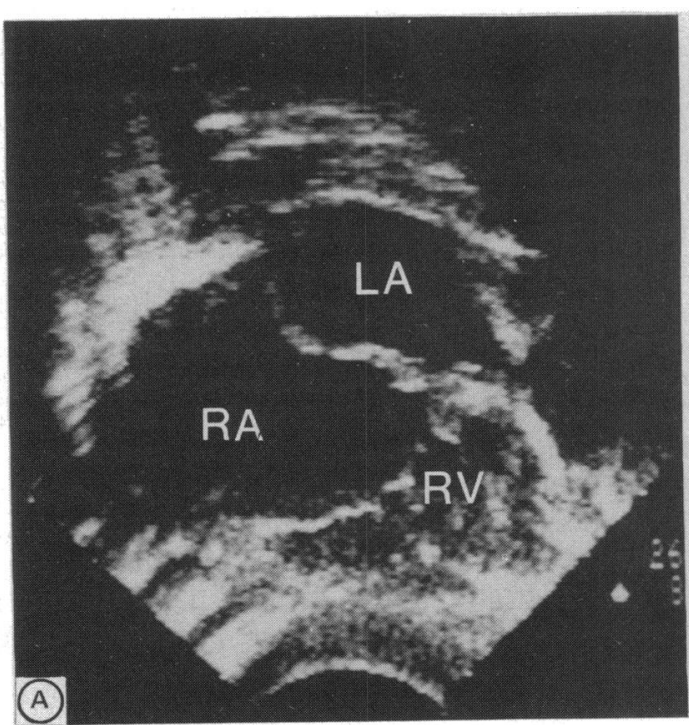

of the septum. When the guide wire and balloon were repositioned more distally dilatation of the atrial septal defect was satisfactory. Atrial pressures and saturations were remeasured after the three dilatations.

\section{Results}

The table shows the effect of balloon dilatation on atrial pressures. In patient 1 dilatation resulted in equalisation of phasic and mean atrial pressures with resolution of hepatic congestion. Echocardiography confirmed that the atrial septum was no longer bowed and that the atrial septal defect was enlarged. He remains well three years after the procedure and is awaiting correction by a Fontan procedure.

The second patient, who was profoundly ill at presentation, showed the greatest initial improvement after dilatation. The mean left atrial pressure was considerably reduced from $32 \mathrm{~mm} \mathrm{Hg}$ to $12 \mathrm{~mm} \mathrm{Hg}$, though an $8 \mathrm{~mm} \mathrm{Hg}$ interatrial gradient persisted. Saturation in the systemic ventricle increased from $40 \%$ to $83 \%$, and his acidosis rapidly resolved. He was easily extubated within 24 hours of the procedure. The persistence of a gradient between the two atria suggested that palliation might be only temporary. He remained well for two months before signs of left atrial hypertension re-

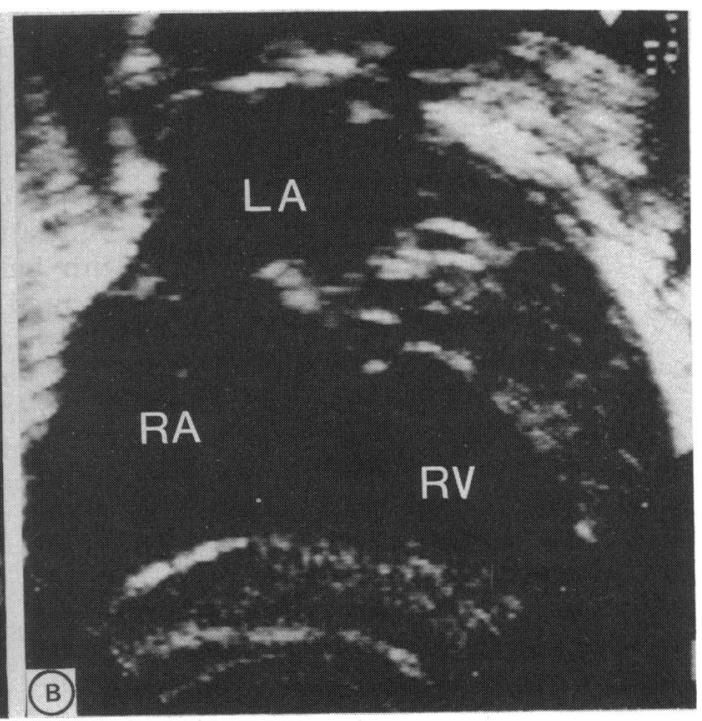

Figure 2 Subcostal cross sectional echocardiographic images of patient 2 before $(A)$ and after $(B)$ balloon dilatation. $(A)$ Before dilatation the bowed to the right. After dilatation $(B)$ the atrial septum was no longer bowed and a central defect with a diameter of about 8 $m m$ had been created. $L A$ left atrium; $R A$, right atrium; $R V$, right ventricle. 
curred. When he was four months old a Blalock-Hanlon atrial septectomy was performed at the time of pulmonary artery banding.

In the third patient with double outlet right ventricle and subpulmonary ventricular septal defect with a pulmonary artery band, the initial dilatation with a $15 \mathrm{~mm}$ balloon had no effect on the atrial pressures. However, after dilatation with a $20 \mathrm{~mm}$ balloon the mean atrial pressure gradient was reduced from 8 to $2 \mathrm{~mm} \mathrm{Hg}$. His maximum resting aortic saturation rose from $81 \%$ to $89 \%$ and his parents reported that his exercise tolerance and rate of growth had increased. An arterial switch procedure and closure of the ventricular septal defect were successful two years later when he was three years old. At operation the persistence of an interatrial communication was confirmed. The defect was approximately $1 \mathrm{~cm}$ in diameter and was situated within the fossa ovalis, with no evidence of tears extending beyond its rim.

\section{Discussion}

Individuals with some forms of congenital heart disease require an adequate interatrial communication for survival. The development of the Rashkind balloon septostomy procedure revolutionised the management of transposition of the great arteries in the neonatal period. ${ }^{1}$ Other lesions, however, such as right or left atrioventricular valve atresia, frequently present after the neonatal period when balloon septostomy may be unsuccessful because of thickening of the atrial septum. Furthermore, even when balloon septostomy has been performed in the neonatal period, progressive restriction of the interatrial communication often develops. ${ }^{3}$ For many years such patients have been palliated either surgically (with the Blalock-Hanlon atrial septectomy) or by Park's blade septostomy procedure in the cardiac catheterisation laboratory. ${ }^{2}$ Both techniques sometimes do not achieve an adequate interatrial communication in the long term. ${ }^{3}$ Furthermore, not all paediatric cardiologists are familiar with the technique of blade septostomy and it can be difficult or even hazardous to introduce a blade catheter into a small left atrium. Anaesthesia for surgical septectomy may also be quite hazardous in some extremely sick infants such as our second patient. The three cases presented show that balloon dilatation of the atrial septum may be an alternative technique for creating a large interatrial communication.

Experience with balloon dilatation of the atrial septum is limited, ${ }^{4-7}$ and we do not know how its safety and efficacy compare with blade septostomy. In our youngest patient the dilatation procedure was initially highly successful in restoring cardiac output and adequate systemic saturations, but palliation was only sustained for two months. It is not known whether a procedure with larger balloons would have resulted in longer palliation. Certainly, the risks of the procedure, such as excessive tearing of the atrial septum beyond the fossa ovalis and damage to the femoral vessels, will be increased if large balloons are used in small infants. The only technical difficulty with the procedure that we have so far experienced was that of distal stripping of the atrial septum along the balloon in patient 3. If the procedure was performed solely under fluoroscopic guidance this stripping might go unnoticed because the position of the balloon might appear to be satisfactory. For this reason cross sectional echocardiographic monitoring should be an integral part of this procedure.

Experimental studies in animals showed that stationary balloon dilatation of the atrial septum produced atrial septal defects within the fossa ovalis without causing tears that extended into the adjacent atrial septum. ${ }^{4}$ In 1987 a successful balloon dilatation procedure of the atrial septum was reported in an infant with transposition of the great arteries. Recently a young adult with primary pulmonary hypertension was palliated by a similar procedure with a $12 \mathrm{~mm} \times 40 \mathrm{~mm}$ balloon catheter after transseptal puncture with a Brockenbrough needle. ${ }^{6}$ Finally, the recent follow up report of the Valvuloplasty and Angioplasty of Congenital Anomalies Registry outlined the results of a number of miscellaneous interventional catheterisation procedures from several centres. ${ }^{7}$ In this review balloon atrial septal dilatation was reported in three infants with hypoplastic left heart syndrome. All three procedures were successful in the short term. One patient had "massive internal bleeding"; no specific details were given.

We showed that balloon dilatation enlarged the atrial septal defect in three children with differing congenital cardiac defects. Further reports of clinical experience are needed to establish the role of this procedure in relation to blade septostomy and surgical septectomy.

1 Neches WH, Mullins CE, McNamara DG. The infant with transposition of the great arteries. II. Results of balloon transposition of the great arteries. 11. Results

2 Park SC, Neches WH, Mullins CE, et al. Blade atrial septostomy: collaborative study. Circulation 1982;66: 258-66.

3 Perry SB, Lang P, Keane JF, Jonas RA, Sanders SP Lock JE. Creation and maintenance of an adequate interatrial communication in left atrioventricular valve atresia or stenosis. Am J Cardiol 1986;58:622-6.

4 Mitchell SE, Kan JS, Anderson JH, White RI Jr, Swindle MM. Atrial septostomy: stationary angioplasty balloon technique [Abstract]. Pediatr Res 1986;20:173A

5 Shrivastava S, Radhakrishnan S, Dev V, Singh LS, Rajani $M$. Balloon dilatation of atrial septum in complete transposition of great artery-a new technique. India Heart $J$ 1987;39:298-300.

6 Hausknecht MJ, Sims RE, Nihill MR, Cashion WR Successful palliation of primary pulmonary hypertension by atrial septostomy. Am J Cardiol 1990;65:1045-6.

7 Mullins CE, Latson LA, Neches WH, Colvin EV, Kan J Balloon dilation of miscellaneous lesions: results of Balloon dilation of miscellaneous lesions: results of Registry. Am J Cardiol 1990;65:802-3.

\section{Addendum}

Since this paper was accepted three further procedures have been successfully performed: two in infants and one in a 17 year old boy with severe primary pulmonary hypertension. 